\title{
Childhood Obesity and Overweight in Ghana: A Systematic Review and Meta-Analysis
}

\author{
Prince Kwaku Akowuah (iD) and Emmanuel Kobia-Acquah \\ Department of Optometry and Visual Science, Kwame Nkrumah University of Science and Technology, Private Mail Bag, \\ University Post Office, Kumasi, Ghana \\ Correspondence should be addressed to Prince Kwaku Akowuah; prince.k.akowuah@gmail.com
}

Received 19 December 2019; Revised 28 February 2020; Accepted 10 March 2020; Published 8 April 2020

Academic Editor: Phillip B. Hylemon

Copyright (C 2020 Prince Kwaku Akowuah and Emmanuel Kobia-Acquah. This is an open access article distributed under the Creative Commons Attribution License, which permits unrestricted use, distribution, and reproduction in any medium, provided the original work is properly cited.

\begin{abstract}
The increasing prevalence of childhood obesity and overweight is considered a public health issue in both developed and developing countries. This systematic review and meta-analysis estimates the prevalence of childhood obesity and overweight in Ghana. A multiple database search was conducted for articles published between January 1, 2001, and October 31, 2019, reporting the prevalence of childhood obesity and overweight in Ghana. Databases searched include PubMed, Google Scholar, Scopus, Cochrane Library, World Health Organization (WHO) Library Information System, and Africa Journals Online. Data were pooled from the articles to calculate an overall estimate of childhood obesity and overweight using a random-effects model after variance stabilization with Freeman-Tukey double arcsine transformation. This review adhered to the Preferred Reporting Items for Systematic Reviews and Meta-Analyses guidelines. Sixteen studies with a combined sample size of 29,160 were included in the review. Analysis indicates that approximately $19 \%$ of children in Ghana either have obesity or are overweight. The prevalence of childhood obesity and overweight was 8.6\% (95\% CI: 4.8\%-13.4\%) and 10.7\% (95\% CI: 5.9\%-16.6\%), respectively. Although not significant, higher obesity (4.6\% vs. $2.6 \%$ ) and overweight (11.0\% vs. $7.2 \%)$ prevalence were estimated for females than for males. There was a significantly higher obesity prevalence estimate (17.4\% vs. $8.9 \%)$ in rural settings than in urban settings $(p=0.0255)$. The high prevalence of childhood obesity and overweight estimated in this review is of worrying concern. It is a significant public health problem that has implications on the health of present and future generations in Ghana and as such calls for proactive measures to be put in place. Also, the driving forces behind the increasing prevalence of childhood obesity in Ghana need to be investigated.
\end{abstract}

\section{Introduction}

Once considered a problem of Western countries, obesity has become a public health problem in low- and middleincome countries too [1-3]. Childhood obesity is of particular concern because it is associated with early onset of risk of diseases such as cardiovascular diseases and diabetes and higher odds of obesity in adulthood [4-7]. Childhood obesity has reached global epidemic levels and is a public health issue in both developing and developed countries. In 2016, approximately 41 million children under age 5 years were overweight or had obesity globally, about $25 \%$ of them in Africa alone [8]. The global prevalence of childhood obesity has been on the rise over the past decades, increasing from $4.2 \%$ in 1990 to $6.7 \%$ in 2010 and is expected to rise to $9.1 \%$ in 2020 [9].

Urbanization and economic development have influenced the increasing trend of adult and childhood obesity [10]. Urbanization has resulted in changes in dietary patterns in both developed and developing countries. Dietary patterns have shifted from traditional nutritious foods, which tend to be high in complex carbohydrate and vegetables, to foods containing high fat and calories [10-12]. In addition to changes in the type of food eaten, there have been changes in the timing of eating as more individuals are eating late into the night mainly due to night/shift work and increasing night lifestyle activities. Urbanization and economic developments have also led to increase in sedentary 
lifestyles. There has been a decrease in physical activities in both developed and developing countries [13]. Advancement in technology has led to relative ease of doing things and moving around; therefore, there is a considerable decrease in opportunities for physical activities [14, 15]. Children spend more time indoors than they do outdoors, playing video games, and partaking in other indoor activities [16-18]. The energy imbalance resulting from the increased high caloric food intake and decreased physical activities is the driving force behind the increase in obesity and overweight over the past decades [19].

The public health significance of obesity and overweight in Ghana is well recognized. Obesity and overweight in Ghana are estimated to have increased over the past decades [20]. The Ghana Demographic and Health Survey reported the increasing prevalence of childhood obesity in Ghana. Prevalence of childhood obesity in children under 5 years was estimated to have increased from less than $1 \%$ in 1988 to $5 \%$ in 2008 [21]. A 7\% prevalence of obesity among children 13-15 years in Ghana was reported by the 2007 Global School-based Student Health Survey [22]. Over the past decades, different studies have reported varying prevalence values for childhood obesity and overweight in Ghana, in the range of $0.7 \%-47.06 \%$ for obesity and $0.8 \%-33.66 \%$ for overweight [23-26]. The varying prevalence of childhood obesity and overweight from the different studies is most likely due to the different geographical regions in which the different studies were conducted, as different regions of the country are known to have different dietary patterns and lifestyle [27-29]. Other possible reasons for the variations among these studies are difference in obesity and overweight diagnostic criteria used and different sampling periods. Despite all these reports and studies estimating the increasing prevalence of childhood obesity and overweight in Ghana, there is no current nationally representative dataset of childhood obesity in Ghana. Although a recent metaanalysis reported obesity and overweight in Ghana [30], this included only studies in Ghanaian adults. There remains no thorough systematic review and meta-analysis reporting the prevalence of childhood obesity and overweight in Ghana. An up-to-date and accurate documentation of prevalence of obesity and overweight in Ghana is needed to inform policy making as well as design and implementation of public health intervention programs. The objective of this review is to summarize and estimate the prevalence of obesity and overweight among children in Ghana using meta-analysis of the current available literature.

\section{Methods}

This review followed the recommendations in the Preferred Reporting Items for Systematic Reviews and Meta-Analyses (PRISMA) statement.

2.1. Literature Search Strategy. A systematic online search of primary literature on childhood obesity and overweight in Ghana was conducted. The databases searched were PubMed, Google Scholar, Scopus, Cochrane Library, World
Health Organization (WHO) Library Information System (WHOLIS), and Africa Journals Online (AJOL). Different variations of search text were used in the literature search, each being an appropriate combination of any of the following words: "childhood OR pediatric OR juvenile OR infantile," "prevalence" AND "obesity OR overweight OR adiposity OR malnutrition” AND “Ghana OR Ghanaian or Africa." All literature searches were performed between 11/ $01 / 2019$ and 11/15/2019. A secondary form of literature search was performed by reviewing all the references of the eligible articles that were obtained from the primary literature, for any relevant publication that might have been missed on the primary literature search.

2.2. Inclusion and Exclusion Criteria. Primary research articles published between January 2001 and October 2019 were included. This was to select articles reporting childhood obesity and overweight in Ghana within the $21^{\text {st }}$ century. Only studies involving participants 19 years and below were included. This was because for this review, we chose to define childhood using the WHO definition. Studies were included only if they reported the prevalence of childhood obesity and overweight separately and used body mass index (BMI) as a means of reporting the prevalence values. If a study does not report prevalence values for obesity or overweight but provides information with which obesity or overweight prevalence could be calculated, it was included. For data pooling, only studies that reported separate prevalence figures for childhood obesity and childhood overweight were included. Finally, only studies with full text of the publication were included.

2.3. Study Screening and Appraisal. For initial screening, studies were selected based on the set inclusion and exclusion criteria using their titles and abstracts. Full-text articles of studies that passed the initial screening were further screened to ensure all inclusion criteria were met. Information extracted from selected studies included authors' names, year of publication, sampling period, study location, sample size, study design, age range of participants, obesity and overweight diagnostic criteria used, and the prevalence of overweight and obesity. A 10-item checklist produced from the Downs and Black checklist [31], and the Strengthening the Reporting of Observational Studies in Epidemiology (STROBE) statement [32] was used to rate and assess the quality of all the full-text articles included in the review.

2.4. Data Analysis. OpenMeta (analyst), an open-source software for meta-analysis [33], and Comprehensive MetaAnalysis software were used for the statistical analysis. A 95\% confidence interval was used in assessing the individual study proportion and pooled effects. The Freeman-Tukey double arcsine transformation was used before pooling to minimize the effects of studies with extremely high or low prevalence estimates on the overall pooled estimates [34]. Assessment of heterogeneity between studies was conducted using Cochran's heterogeneity statistics (Q) and degree of inconsistency $\left(I^{2}\right)$. The $I^{2}$ statistic provides an estimate of the 
percentages of heterogeneity across studies that is truly due to differences between studies but not chance. $I^{2}>60 \%$ was regarded as meaningful heterogeneity. In cases of meaningful heterogeneity, analyses of pooled effects were performed with the random-effects model [35]. Metaregression analysis was conducted to explore the association between factors such as gender, study setting, study location, and prevalence of childhood obesity and overweight. The robustness of the pooled effects and potential outliers were assessed with the leave-one-out sensitivity analysis. The leave-one-out sensitivity analysis evaluates the contribution of each study to the total pooled estimate [36]. The funnel plot was used to evaluate the presence of publication bias and confirmed by Egger's test. For all statistical analysis, a $p$ value $<0.05$ was considered statistically significant.

\section{Results}

Two thousand and twenty-three (2023) articles were identified through search of the database. Five hundred and ninety-nine (599) were identified as duplicates and excluded based on their titles. Through screening against the preset criteria, 1401 articles were excluded based on their titles and abstracts, leaving 23 full-text articles to assess for eligibility; articles excluded at this stage were either from studies not conducted in Ghana, studies conducted in Ghana but in adults, or studies conducted in Ghana but the focus was not on reporting obesity or overweight prevalence. Seven of the 23 articles were excluded for the following reasons: one article did not report prevalence values for obesity or overweight, 1 article reported a combined prevalence value for Ghana and Uganda, 1 article included participants older than 19 years, 3 articles reported combined prevalence values for obesity and overweight, and 2 articles were from the same sample so one was excluded. Total number of articles included in the review was 16. The PRISMA flowchart detailing the steps in obtaining the articles included in this review is shown in Figure 1.

Table 1 provides a summary of the details of the studies included in the review. All studies were published between 2012 and 2019, with 10 of them published within the last 5 years. For 9 of the studies included in the review, data collection was conducted between 2007 and 2016; 7 of the studies did not state the period during which data were collected for the studies. The studies were conducted in the various regions of Ghana as follows: 4 studies were conducted in Ashanti Region; 4 studies in Greater Accra Region; 2 studies in the Volta Region; 1 study each in the Eastern, Central, and Northern Regions; 1 study in both Ashanti and Greater Accra Regions; and 2 studies across the country. The sample sizes of the included studies ranged from 270 to 7,550 with a combined total sample size of 29,160 .

3.1. Prevalence of Childhood Obesity in Ghana. Prevalence values of childhood obesity in Ghana were retrieved from 12 articles. The reported prevalence of childhood obesity in these studies ranged from $0.7 \%$ to $47.06 \%$. The combined sample size of the 12 studies was 20,198 . The pooled estimate of the prevalence of childhood obesity in Ghana was $8.6 \%$
(95\% CI: 4.8\%-13.4\%). Heterogeneity between studies determined by $I^{2}$ was $98.97 \%(p<0.001)$ (Figure 2$)$. A leaveone-out sensitivity analysis also revealed that the pooled estimate was most impacted by the prevalence values from Amoh and Appiah-Brempong [25] (Figure 3). The funnel plot revealed no publication bias in obesity prevalence reports (Figure 4). This was confirmed by Egger's test (0.4711).

Definition of obesity and overweight:

(1) WHO: obesity-BMI>2 standard deviation above the WHO growth standard median (age 5-19 years); overweight-BMI $>1$ standard deviation above the WHO growth standard median [49]

(2) US CDC: obesity-BMI $\geq 95$ percentile; overweight $-\mathrm{BMI} \geq 85$ percentile [50]

(3) IOTF: obesity-BMI $\geq 30$; overweight-BMI $\geq 25$ [51]

* Study locations were defined based on the previous 10 administrative regions of Ghana. Greater Accra Region is the national capital of Ghana and is in the southern part of Ghana. The Greater Accra Region is the most urbanized region in Ghana with about $90 \%$ of the populace living in urban areas but it is the smallest region by land size [52]. The Ashanti Region is in southern Ghana and is the most populous region. It is the third largest region by land size. The Ashanti Region is a largely urban region, and the economy is largely driven by extraction and processing of industrial mineral and agricultural commodities [53]. The Volta Region is in southern Ghana. It is a mostly rural region with about $64 \%$ of the populace living in rural areas. The economy of the Volta Region is largely driven by agriculture [54]. The Eastern Region is also in southern Ghana and has a predominantly rural population, with about $57 \%$ of the populace living in rural areas. The economy of the Eastern Region is hugely dominated by its high electricity generation capacity. The Northern Region is in the northern part of Ghana and is the largest region by land size. The Northern Region has a predominantly rural population, with about $70 \%$ of the populace living in rural areas. The economy of the Northern Region is driven predominantly by agriculture [55].

Prevalence values of childhood obesity among males were pooled from 6 articles included in the review. The reported prevalence of childhood obesity among males in these studies ranged from $0.6 \%$ to $9.3 \%$. The pooled estimate of childhood obesity among males was 3.5\% (95\% CI: $1.4 \%-$ $\left.6.3 \% ; I^{2}=95.86 \%, p<0.001\right)$. For females, the prevalence value for childhood obesity was pooled from 6 studies. The prevalence of childhood obesity among females reported in the studies ranged from $1.5 \%$ to $14.7 \%$. The pooled estimate of childhood obesity among females was $4.6 \%$ (95\% CI: $\left.1.9 \%-8.4 \% ; I^{2}=97.08, p<0.001\right)$. There was no statistically significant difference in the prevalence of obesity among males and females $(p=0.68)$.

The prevalence of childhood obesity in rural locations was pooled from 3 articles. The reported prevalence of childhood obesity in rural locations ranged from $5.3 \%$ to $47.06 \%$. The pooled estimate of childhood obesity in rural locations was $17.4 \%$ (95\% CI: $1.5 \%-44.8 \%$; $I^{2}=99.06 \%$, $p<0.001)$. The prevalence of childhood obesity in urban 


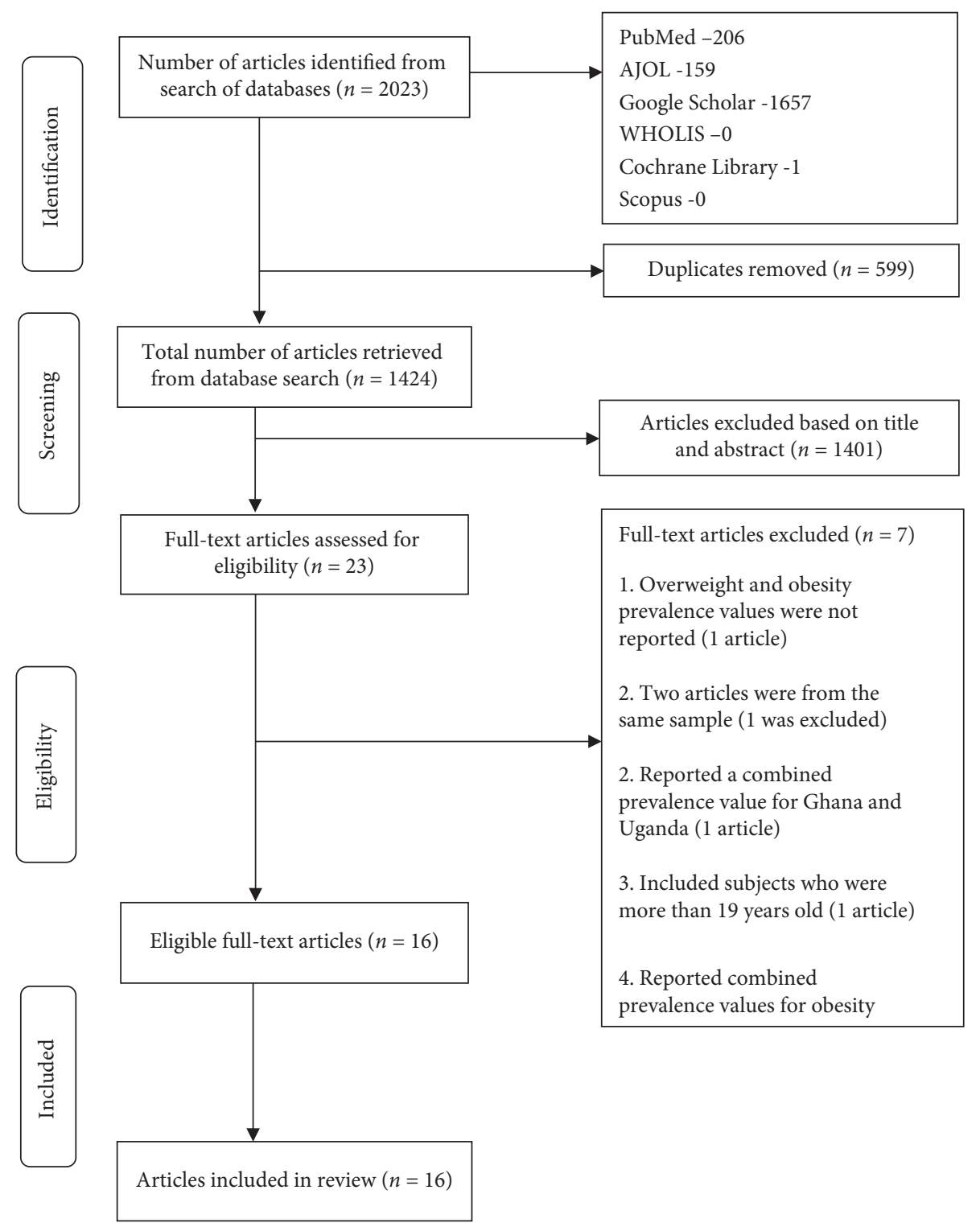

FIgUre 1: PRISMA flowchart of steps in identifying studies.

locations was pooled from seven articles and ranged from $4.4 \%$ to $26.5 \%$. The pooled estimate of childhood obesity in urban location was $8.9 \%$ (95\% CI: $4.8 \%-14.1 \%$; $I^{2}=95.44 \%$, $p<0.001)$. There was a statistically significant difference in the prevalence of childhood obesity in rural and urban settings $(p=0.0255)$.

The prevalence of childhood obesity in the Ashanti Region was pooled from 4 articles and was estimated to be 12.5\% (95\% CI: $\left.1.4 \%-31.9 \% ; I^{2}=98.87 \%, p<0.001\right)$. The prevalence of childhood obesity in the Greater Accra Region was also pooled from 4 articles and was estimated to be 12.1\% (95\% CI: $7.9 \%-17.0 \% ; I^{2}=74.09 \%, p<0.001$ ).

\subsection{Prevalence of Childhood Overweight in Ghana.} Prevalence values of childhood overweight in Ghana were retrieved from 15 articles. The total sample size was 28,900. The reported prevalence of childhood overweight in these studies ranged from $0.8 \%$ to $33.7 \%$. The pooled estimate of the prevalence of childhood overweight in Ghana was $10.7 \%$ (95\% CI: 5.9-16.6). Heterogeneity between studies determined by $I^{2}$ was $99.47 \%(p<0.001)$ (Figure 5). A leave-oneout sensitivity analysis also revealed that the pooled estimate was most impacted by the prevalence values from Amoh and Appiah-Brempong [25] (Figure 6). The funnel plot revealed publication bias, depicted by the asymmetrical display of prevalence values reported by the various studies (Figure 7); this was confirmed by Egger's test $(p=0.043)$.

Prevalence values of childhood overweight among males were pooled from 6 articles. The reported prevalence of childhood overweight among males in these studies ranged from $2.1 \%$ to $16.3 \%$. The pooled estimate of childhood overweight among males was 7.2\% (95\% CI: $4.0 \%-11.4 \%$; $\left.I^{2}=96.48 \%, p<0.001\right)$. For females, the prevalence value for childhood overweight was pooled from 6 studies. The prevalence of childhood overweight among females reported 


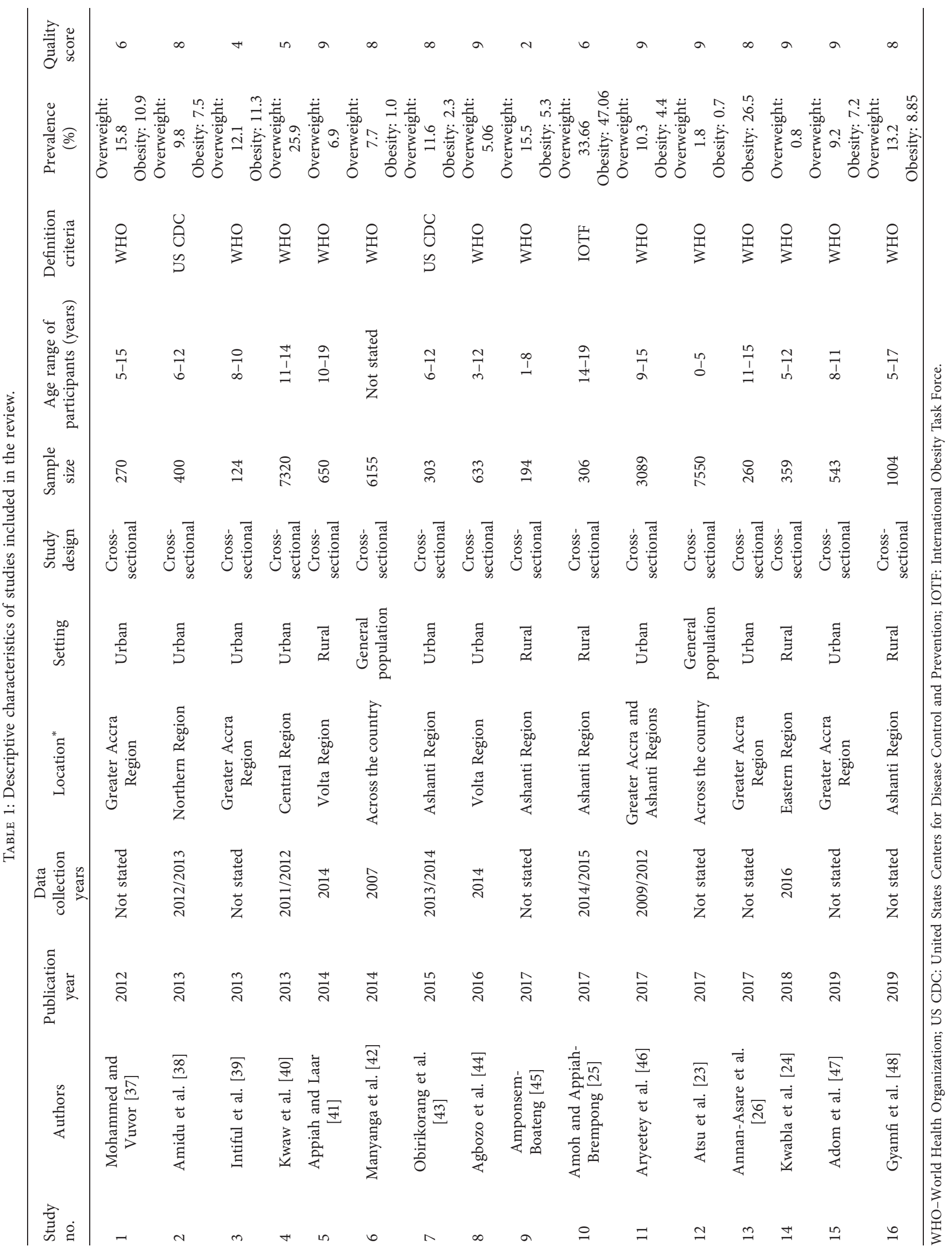




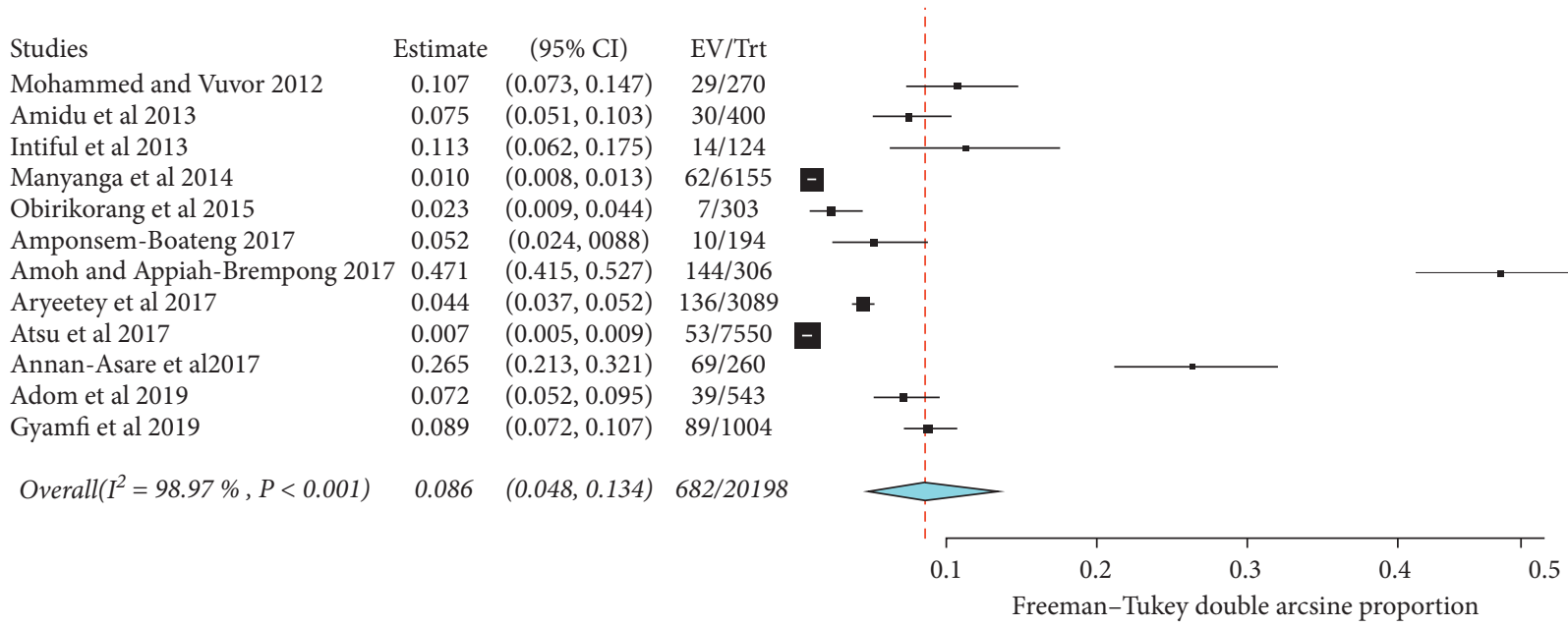

FIGURE 2: Forest plot of studies reporting the prevalence of childhood obesity in Ghana.

$\begin{array}{lc}\text { Studies } & \text { Estimate }(95 \% \mathrm{CI}) \\ & \\ \text { Overall } & 0.084(0.067,0.100) \\ & \\ \text { Mohammed and Vuvor } & 0.081(0.065,0.098) \\ \text { Amidu et al } & 0.084(0.067,0.101) \\ \text { Intiful et al } & 0.082(0.065,0.099) \\ \text { Manyanga et al } & 0.110(0.078,0.142) \\ \text { Obirikorang et al } & 0.091(0.073,0.108) \\ \text { Amponsem-Boateng } & 0.086(0.070,0.103) \\ \text { Amoh and Appiah-Brempong } & 0.059(0.046,0.073) \\ \text { Aryeetey et al } & 0.088(0.071,0.105) \\ \text { Atsu et al } & 0.110(0.079,0.141) \\ \text { Annan-Asare et al } & 0.072(0.057,0.088) \\ \text { Adom et al } & 0.084(0.068,0.101) \\ \text { Gyamfi et al } & 0.081(0.065,0.098)\end{array}$

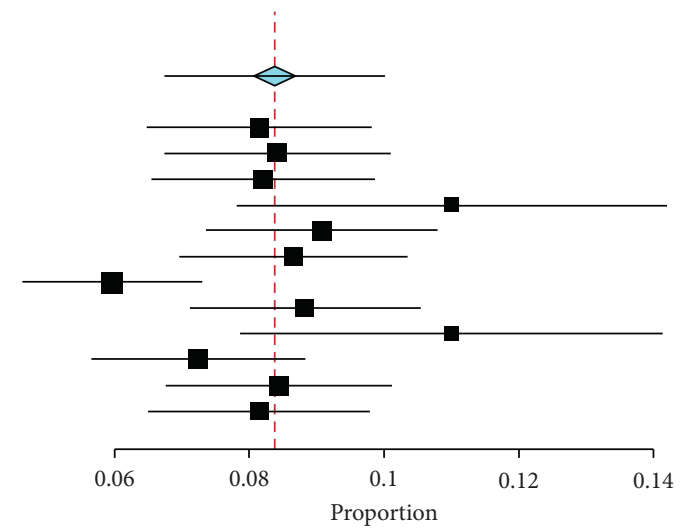

FIGURE 3: Leave-one-out sensitivity plot of studies reporting the prevalence of childhood obesity in Ghana.

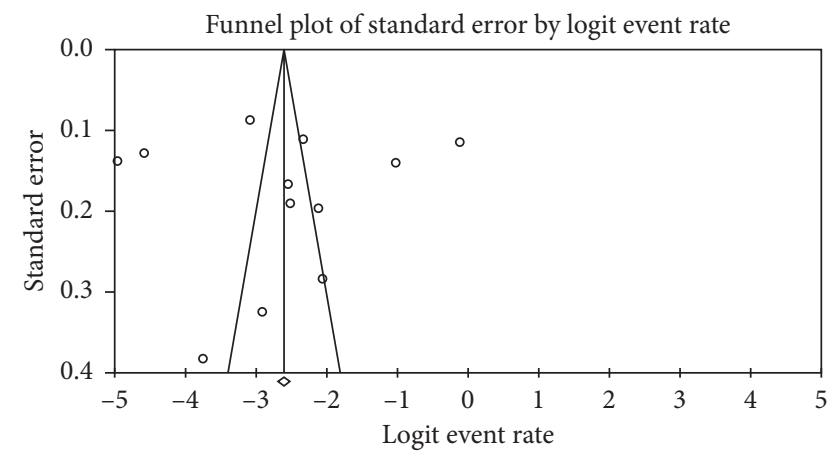

FIGURE 4: Funnel plot of studies reporting the prevalence of childhood obesity in Ghana.

in the studies ranged from $1.4 \%$ to $19.4 \%$. The pooled estimate of childhood overweight among females was $10.9 \%$ (95\% CI: 4.0\%-20.4\%; $I^{2}=99.04 \%, p<0.001$ ). There was no statistically significant difference in the prevalence of overweight among males and females $(p=0.181)$.

The prevalence of childhood overweight in rural locations was pooled from 5 articles and ranged from $0.8 \%$ to $33.7 \%$. The pooled estimate of childhood overweight in rural locations was $11.8 \%$ (95\% CI: $4.1 \%-22.7 \% ; I^{2}=98.01 \%$, $p<0.001)$. The prevalence of childhood overweight in urban locations was estimated from eight articles and ranged from $5.1 \%$ to $25.9 \%$. The pooled estimate of childhood overweight in urban location was $12.0 \%$ (95\% CI: $6.3 \%-19.1 \% ; I^{2}=98.84$ $\%, p<0.001)$. There was no significant difference in the prevalence of overweight in rural and urban settings $(p=0.692)$.

The prevalence of childhood overweight in the Ashanti Region was pooled from 4 articles and was estimated to be 17.7\% (95\% CI: 9.7\%-27.6\%; $\left.I^{2}=95.33 \%, p<0.001\right)$. The prevalence of childhood overweight in the Greater Accra Region was also pooled from 3 articles and was estimated to 12.1\% (95\% CI: 7.7\%-17.0\%; $I^{2}=74.09 \%, p=0.021$ ).

\section{Discussion}

The current study provides the first systematic review and meta-analysis on childhood obesity and overweight in Ghana. The overall prevalence of childhood obesity and overweight in Ghana was $8.6 \%$ and $10.7 \%$, respectively. This is comparable to the prevalence values reported by other regional studies in Africa [56]. These prevalence values are however higher compared to the expected value for developing countries and the world at large. Combined 


Studies
Mohammed and Vuvor 2012
Amidu et al 2013
Intiful et al 2013
Kwaw et al 2013
Appiah and Laar 2014
Manyanga et al 2014
Obirikorang et al 2015
Agbozo et al 2016
Amponsem-Boateng 2017
Amoh and Appiah-Brempong 2017
Aryeetey et al 2017
Atsu et al 2017
Kwabla et al 2018
Adom et al 2019
Gyamfi et al 2019
Overall $\left(I^{2}=99.47 \%, P<0.001\right)$

Studies

$0.159(0.118,0.205)$ $0.098(0.070,0.129)$

$0.121(0.069,0.185)$

$0.259(0.249,0.269)$

$0.069(0.051,0.090)$

$0.077(0.070,0.084)$

$0.116(0.082,0.154)$

$0.051(0.035,0.069)$

$0.155(0.107,0.209)$

$0.337(0.285,0.391)$

$0.103(0.092,0.114)$

$0.018(0.015,0.021)$

$0.008(0.001,0.021)$

$0.092(0.069,0.118)$

$0.132(0.112,0.154)$

$0.107(0.059,0.166)$
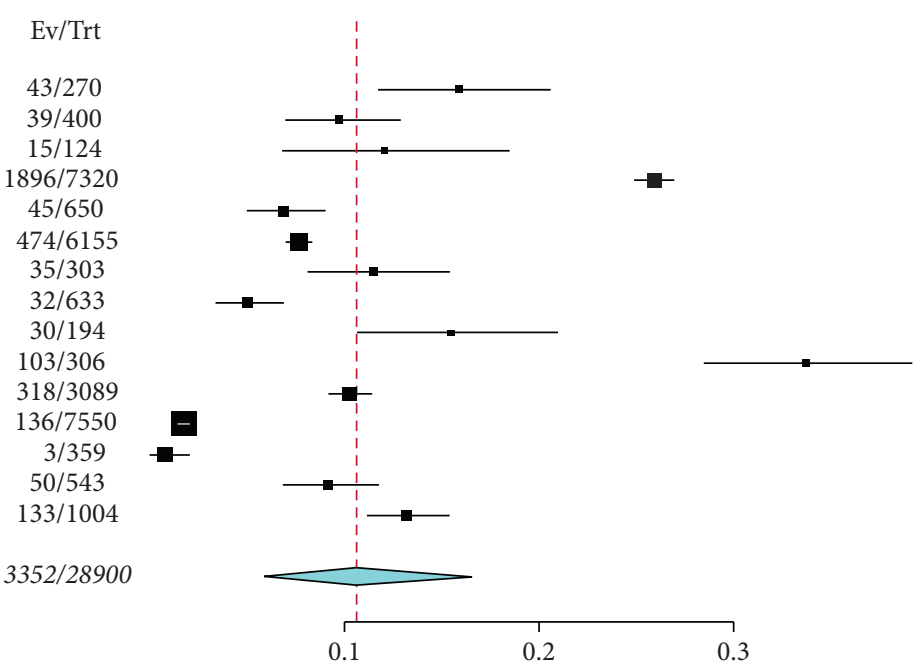

Freeman-Tukey double arcsine proportion

FIGURE 5: Forest plot of studies reporting the prevalence of childhood overweight in Ghana.

$\begin{array}{lc}\text { Studies } & \text { Estimate }(95 \% \mathrm{CI}) \\ \text { Overall } & 0.118(0.076,0.160) \\ & \\ \text { Mohammed and Vuvor } & 0.115(0.072,0.158) \\ \text { Amidu et al } & 0.119(0.076,0.163) \\ \text { Intiful et al } & 0.118(0.075,0.161) \\ \text { Kwaw et al } & 0.104(0.078,0.131) \\ \text { Appiah and Laar } & 0.121(0.078,0.165) \\ \text { Manyanga et al } & 0.121(0.071,0.172) \\ \text { Obirikorang et al } & 0.118(0.075,0.161) \\ \text { Agbozo et al } & 0.123(0.079,0.167) \\ \text { Amponsem-Boateng } & 0.115(0.072,0.158) \\ \text { Amoh and Appiah-Brempong } & 0.103(0.061,0.146) \\ \text { Aryeetey et al } & 0.119(0.074,0.164) \\ \text { Atsu et al } & 0.125(0.080,0.171) \\ \text { Kwabla et al } & 0.126(0.080,0.172) \\ \text { Adom et al } & 0.120(0.076,0.163) \\ \text { Gyamfi et al } & 0.117(0.074,0.160)\end{array}$

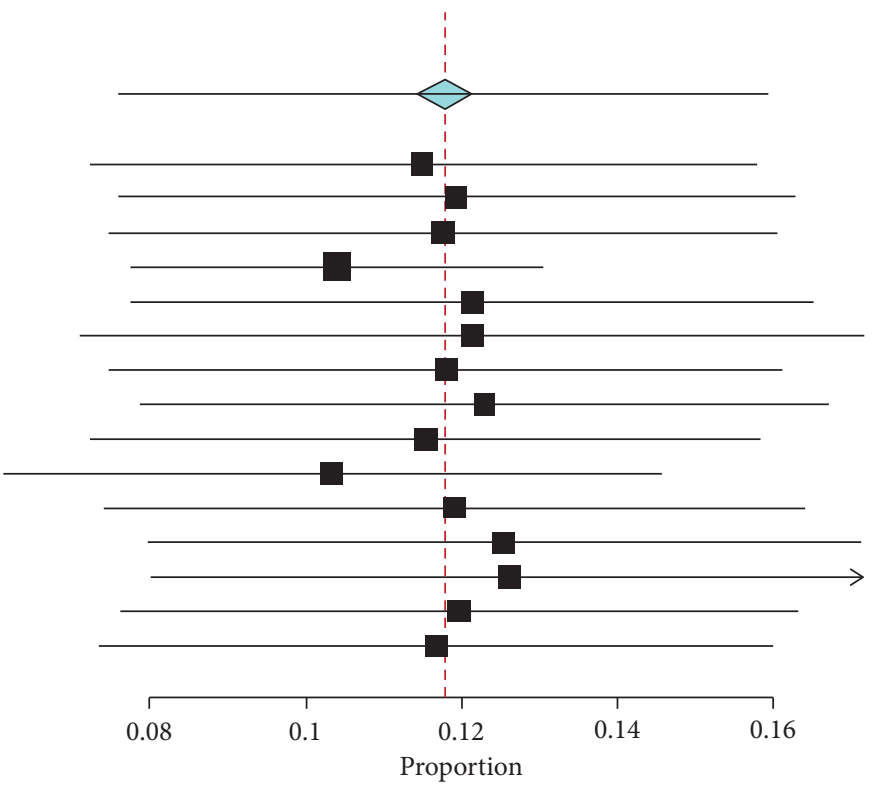

FIGURE 6: Leave-one-out plot sensitivity plot of studies reporting the prevalence of childhood overweight in Ghana.

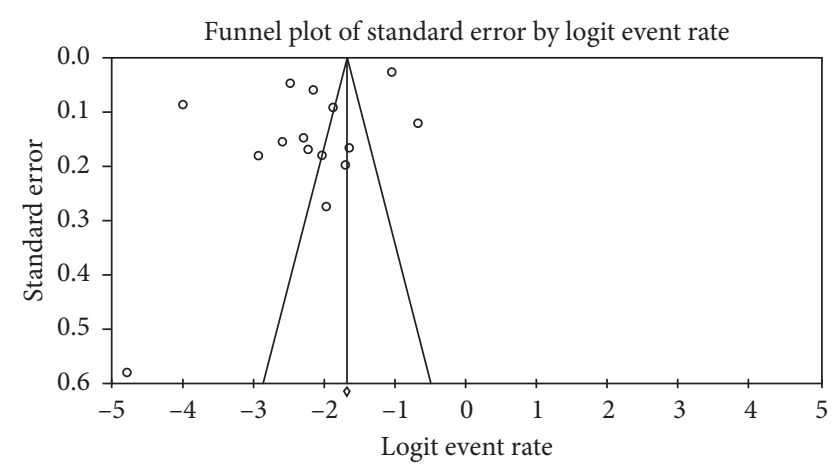

FIGURE 7: Funnel plot of studies reporting the prevalence of childhood overweight in Ghana. prevalence of obesity and overweight in developing countries was $6.1 \%$ in 2010 and is expected to reach $8.6 \%$ by 2020 [9]. This highlights the extent of the childhood obesity and overweight burden in Ghana and the need for public health interventions geared towards fighting this public health issue.

Over the past decades, the focus of almost all nutritional programs in developing countries has been on undernutrition, as undernutrition is well-established and recognized problem of the developing world. While undernutrition still remains a problem for some developing countries, another nutritional problem being faced by most developing countries is obesity and overweight. For a long time, obesity has been seen as a problem of affluent and developed 
countries, but this is changing. Due to urbanization and economic development, the prevalence of childhood obesity and obesity in general is increasing in developing countries like Ghana. The rise in obesity in developing countries has largely been influenced by changes in dietary patterns. People are no longer eating the traditional nutritious food as consumption of easy and readily available high-fat and caloric content foods is fast increasing. In Ghana, there has been a rise in the fast food franchise especially in big cities, with a lot of Ghanaians patronizing fast food restaurants. The influence of fast food consumption on rising cases of obesity is well established in both developed and developing countries [57-62]. Another factor fueling the rise in obesity is the increase in sedentary lifestyle of people, especially in urban centers. There has been a decrease in physical activities in both developed and developing countries [13]. Advancement in technology has led to relative ease of doing things and moving around; therefore, there is a considerable decrease in opportunities for physical activities [14, 15]. Children spend more time indoors than they do outdoors, playing video games, and partaking in other indoor activities [16-18]. The energy imbalance resulting from the increased high caloric food intake and decreased physical activities is the driving force behind the increase in obesity and overweight over the past decades [19]. The paradoxical coexistence of undernutrition and overnutrition in most developing countries is disturbing public health problem, as most groups within these developing countries have low socioeconomic strength and hence will lack the financial ability to afford nutritionally rich food but are at the same time more likely to consume cheaper energy-dense foods that are known to cause obesity [63].

Obesity in general seems to be a rising problem for Ghana. A recent review reported the prevalence of obesity and overweight in adults 18 years above to be $17.1 \%$ and $25.6 \%$, respectively. Thus, Ghana appears to have a high prevalence of both childhood and adulthood obesity and overweight, and these patterns will continue to increase given the current trend of dietary changes in Ghana. The high prevalence of childhood and adulthood obesity is a concern to clinical and public health experts, nutritional scientists, and government due to the potential effects it could have on the health of citizens. With the high prevalence of obesity, Ghana stands the unfortunate possibility of rising numbers of diabetes, hypertension, and other cardiovascular diseases which are already major reasons for frequent visits to health facilities among the older population.

Contrary to other studies, although point estimates for childhood obesity and overweight were generally higher in females than in males, no significant gender difference in childhood obesity or overweight was found in the current meta-analysis. Reports on the gender difference in childhood obesity or overweight prevalence are inconsistent; some studies report higher prevalence in males [64, 65], others report higher prevalence in females [66] while some report no gender difference in childhood obesity or overweight prevalence [67]. In a similar study involving a meta-analysis of obesity and overweight among school-going children in
Africa, no gender difference in obesity or overweight prevalence was reported [56]. While there is no coherent gender-related pattern in childhood obesity and overweight, a consistent gender-related pattern is observed in obesity and overweight among adults, where the prevalence is frequently higher in females compared to males [1, 67-69]. This suggests an age-gender interaction in obesity and overweight $[64,70]$.

In contrast to other studies, the current review reports a significantly higher prevalence of obesity in rural areas than in urban areas. Almost all other studies consistently report higher estimates of obesity prevalence in urban areas compared to rural areas [71-73]. The apparently contrary report from the current review might be to the low number of studies used in pooling the prevalence estimates of obesity for the rural area. As such, one of the studies, which reported a higher prevalence value, skewed the pooled estimate.

A key limitation of this review is the regional imbalance in the studies included. Even though efforts were made to include studies from across the country, over half of the studies used in this review were conducted in two regions (Ashanti and Greater Accra Regions). Also, some of the studies included were not originally designed to assess obesity and overweight prevalence and as such might not have put in place measures to prevent bias in reporting the prevalence. Also, it is acknowledged that some relevant studies might have been missed as they might have been published in local journals that did not appear in our literature search. Most of the studies did not report prevalence values for obesity or overweight across sociodemographic characteristics such as gender and setting. Hence, not enough articles were used in calculating the pooled estimates across those sociodemographic characteristics. Despite all these limitations, the prevalence values for childhood obesity and overweight estimated by this review should be a close representation of the situation within the current or immediate past decade as sampling and publication of all studies occurred within the current or immediate past decade.

\section{Conclusion}

The high prevalence of childhood obesity and overweight estimated in this review is of worrying concern. It is a significant public health problem that has implications on the health of present and future generations in Ghana and as such calls for proactive measures to be put in place. Also, the driving forces behind the increasing prevalence of childhood obesity in Ghana need to be investigated.

\section{Conflicts of Interest}

The authors have no conflicts of interest to declare.

\section{Supplementary Materials}

Forest plot subanalysis of gender and study setting. (Supplementary Materials) 


\section{References}

[1] M. Ng, T. Fleming, M. Robinson et al., "Global, regional, and national prevalence of overweight and obesity in children and adults during 1980-2013: a systematic analysis for the global burden of disease study," Lancet, vol. 384, no. 9945, 2013.

[2] Y. Wang and T. Lobstein, "Worldwide trends in childhood overweight and obesity," International Journal of Pediatric Obesity, vol. 1, no. 1, 2006.

[3] T. Lobstein, L. Baur, and R. Uauy, "Obesity in children and young people: a crisis in public health," Obesity Reviews, vol. 5, no. s1, 2004.

[4] J. J. Reilly and J. Kelly, "Long-term impact of overweight and obesity in childhood and adolescence on morbidity and premature mortality in adulthood: systematic review," International Journal of Obesity, vol. 35, no. 7, 2011.

[5] C. Maffeis and L. Tatò, "Long-term effects of childhood obesity on morbidity and mortality," Hormone Research in Paediatrics, vol. 55, no. 1, 2001.

[6] A. S. Singh, C. Mulder, J. W. R. Twisk, W. Van Mechelen, and M. J. M. Chinapaw, "Tracking of childhood overweight into adulthood: a systematic review of the literature," Obesity Reviews, vol. 9, no. 5, 2008.

[7] M. Simmonds, J. Burch, A. Llewellyn et al., "The use of measures of obesity in childhood for predicting obesity and the development of obesity-related diseases in adulthood: a systematic review and meta-analysis," Health Technology Assessment, vol. 19, no. 43, 2015.

[8] World Health Organization, Obesity and Overweight: Key Facts, World Health Organization, Geneva, Switzerland, 2018.

[9] Y. Wang and H. Lim, "The global childhood obesity epidemic and the association between socio-economic status and childhood obesity," International Review of Psychiatry, vol. 24, no. 3, 2012.

[10] A. Drewnowski and B. M. Popkin, "The nutrition transition: new trends in the global diet," Nutrition Reviews, vol. 55, pp. 31-43, 2009.

[11] C. Hawkes, "Uneven dietary development: linking the policies and processes of globalization with the nutrition transition, obesity and diet-related chronic diseases," Globalization and Health, vol. 2, p. 4, 2006.

[12] R. Ronto, J. H. Y. Wu, and G. M. Singh, "The global nutrition transition: trends, disease burdens and policy interventions," Public Health Nutrition, vol. 21, pp. 2267-2270, 2018.

[13] B. M. Popkin, L. S. Adair, and S. W. Ng, "Global nutrition transition and the pandemic of obesity in developing countries," Nutrition Reviews, vol. 70, no. 1, pp. 3-21, 2012.

[14] A. C. Bell, K. Ge, and B. M. Popkin, "The road to obesity or the path to prevention: motorized transportation and obesity in China," Obesity Research, vol. 10, no. 4, 2002.

[15] K. L. Monda, L. S. Adair, F. Zhai, and B. M. Popkin, "Longitudinal relationships between occupational and domestic physical activity patterns and body weight in China," European Journal of Clinical Nutrition, vol. 62, no. 11, pp. 13181325, 2008.

[16] E. A. Hodges, C. Smith, S. Tidwell, and D. Berry, "Promoting physical activity in preschoolers to prevent obesity: a review of the literature," Journal of Pediatric Nursing, vol. 28, no. 1, pp. 3-19, 2013.

[17] K. D. Hesketh and K. J. Campbell, "Interventions to prevent obesity in 0-5 year olds: an updated systematic review of the literature," Obesity, vol. 18, no. n1s, 2010.

[18] L. Tremblay, C. Boudreau-Larivière, and K. Cimon-Lambert, "Promoting physical activity in preschoolers: a review of the guidelines, barriers, and facilitators for implementation of policies and practices," Canadian Psychology/Psychologie canadienne, vol. 53, no. 4, pp. 280-290, 2012.

[19] B. Caballero, "The global epidemic of obesity: an overview," Epidemiologic Reviews, vol. 29, no. 1, 2007.

[20] F. Ofei, "Obesity-a preventable disease," Ghana Medical Journal, vol. 39, no. 3, pp. 98-101, 2005.

[21] Ghana Statistical Service, Ghana health service, ICF International. Ghana Demographic and Health Survey 2014, Ghana Statistical Service, Accra, Ghana, 2015.

[22] World Health Organization, Global School-Based Student Health Survey, World Health Organization, Geneva, Switzerland, 2007.

[23] B. K. Atsu, C. Guure, and A. K. Laar, "Determinants of overweight with concurrent stunting among Ghanaian children," BMC Pediatrics, vol. 17, no. 1, 2017.

[24] M. P. Kwabla, C. Gyan, and F. Zotor, "Nutritional status of inschool children and its associated factors in Denkyembour District, eastern region, Ghana: comparing schools with feeding and non-school feeding policies," Nutrition Journal, vol. 17, no. 1, 2018.

[25] I. Amoh and E. Appiah-Brempong, "Prevalence and risk factors of obesity among senior high school students in the Adansi North district of Ghana," International Journal of Community Medicine and Public Health, vol. 4, no. 10, 2017.

[26] J. Annan-Asare, M. Asante, and A. G. B. Amoah, "Obesity and its correlates among junior high school children in the Accra metropolis," Journal of Nutrition and Health Sciences, vol. 4, no. 2, 2017.

[27] L. K. Frank, J. Kröger, M. B. Schulze, G. Bedu-Addo, F. P. Mockenhaupt, and I. Danquah, "Dietary patterns in urban Ghana and risk of type 2 diabetes," British Journal of Nutrition, vol. 112, no. 1, 2014.

[28] A. R. Abizari and Z. Ali, "Dietary patterns and associated factors of schooling Ghanaian adolescents," Journal of Health, Population and Nutrition, vol. 38, no. 1, 2019.

[29] I. De Jager, K. E. Giller, and I. D. Brouwer, "Food and nutrient gaps in rural Northern Ghana: does production of smallholder farming households support adoption of food-based dietary guidelines?" PLoS One, vol. 13, no. 9, Article ID e0204014, 2018.

[30] R. Ofori-Asenso, A. A. Agyeman, A. Laar, and D. Boateng, "Overweight and obesity epidemic in Ghana - a systematic review and meta-analysis," BMC Public Health, vol. 16, no. 1, 2016.

[31] S. H. Downs and N. Black, "The feasibility of creating a checklist for the assessment of the methodological quality both of randomised and non-randomised studies of health care interventions," Journal of Epidemiology \& Community Health, vol. 52, pp. 377-384, 1998.

[32] E. von Elm, D. G. Altman, M. Egger, S. J. Pocock, P. C. Gøtzsche, and J. P. Vandenbroucke, "The strengthening the reporting of observational studies in epidemiology (STROBE) statement: guidelines for reporting observational studies," International Journal of Surgery, vol. 12, no. 12, pp. 1495-1499, 2014.

[33] B. C. Wallace, I. J. Dahabreh, T. A. Trikalinos, J. Lau, P. Trow, and C. H. Schmid, "Closing the gap between methodologists and end-users: $\mathrm{R}$ as a computational back-end," Journal of Statistical Software, vol. 49, no. 5, 2012.

[34] J. J. Miller, "The inverse of the freeman-tukey double arcsine transformation," The American Statistician, vol. 32, no. 4, p. 138, 1978.

[35] J. P. T. Higgins, S. G. Thompson, J. J. Deeks, and D. G. Altman, "Measuring inconsistency in meta-analyses," BMJ, vol. 327, no. 7414, pp. 557-560, 2003. 
[36] J. P. T. Higgins, "Commentary: heterogeneity in meta-analysis should be expected and appropriately quantified," International Journal of Epidemiology, vol. 37, no. 5, 2008.

[37] H. Mohammed and F. Vuvor, "Prevalence of childhood overweight/obesity in basic school in Accra," Ghana Medical Journal, vol. 46, no. 3, 2012.

[38] N. Amidu, W. Owiredu, M. Saaka et al., "Determinants of childhood obesity among basic school children aged 6-12 years in Tamale Metropolis," Journal of Medical and Biomedical Sciences, vol. 2, no. 3, 2013.

[39] F. Intiful, L. Ogyiri, a moako-Mensah, and R. Steele-Dadzie, "Comparative study of nutritional status of boarding and nonboarding pupils in selected schools in the ACCRA metropolis," Annals of Nutrition and Metabolism, vol. 63, 2013.

[40] K. Emmanuel, "Assessment of the nutritional status of junior high school students-evidence from mfantseman municipality of Ghana," Science Journal of Public Health, vol. 1, no. 5, 2013.

[41] A. Prince and A. Laar, "Nutritional status of school-age children in the nkwanta south district -Volta region of Ghana," European Scientific Journal, vol. 10, no. 30, 2014.

[42] T. Manyanga, H. El-Sayed, D. T. Doku, and J. R. Randall, “The prevalence of underweight, overweight, obesity and associated risk factors among school-going adolescents in seven African countries," BMC Public Health, vol. 14, no. 1, 2014.

[43] C. Obirikorang, E. Anto, R. Ngala, and E. Gyamfi, "The prevalence OF childhood obesity and lifestyle-associated risk factors using anthropometric measurements among primary schools IN the kumasi metropolis, Ghana," Innovative Journal of Medical and Health Science, vol. 4, 2015.

[44] F. Agbozo, P. Atito, and A. Abubakari, "Malnutrition and associated factors in children: a comparative study between public and private schools in Hohoe Municipality, Ghana," BMC Nutrition, vol. 2, no. 1, 2016.

[45] C. Amponsem-Boateng, "Prevalence of malnutrition among children 1-8 Years in Ghana: amansie west district of Ghana," World Wide Journal of Multidisciplinary Research and Development, vol. 3, pp. 187-191, 2017.

[46] R. Aryeetey, A. Lartey, G. S. Marquis, H. Nti, E. Colecraft, and P. Brown, "Prevalence and predictors of overweight and obesity among school-aged children in urban Ghana," $B M C$ Obesity, vol. 4, no. 1, 2017.

[47] T. Adom, A. De Villiers, T. Puoane, and A. P. Kengne, "Prevalence and correlates of overweight and obesity among school children in an urban district in Ghana," BMC Obesity, vol. 6 , no. 1, 2019.

[48] D. Gyamfi, C. Obirikorang, E. Acheampong et al., "Weight management among school-aged children and adolescents: a quantitative assessment in a Ghanaian municipality," $B M C$ Pediatrics, vol. 19, no. 1, 2019.

[49] M. De Onis, A. W. Onyango, E. Borghi, A. Siyam, C. Nishida, and J. Siekmann, "Development of a WHO growth reference for school-aged children and adolescents," Bulletin of the World Health Organization, vol. 85, no. 9, 2007.

[50] Centers for Disease Control and Prevention, Defining Childhood Obesity, Centers for Disease Control and Prevention, Atlanta, GA, USA, 2018, https://www.cdc.gov/ obesity/childhood/defining.html.

[51] T. J. Cole, M. C. Bellizzi, K. M. Flegal, and W. H. Dietz, "Establishing a standard definition for child overweight and obesity worldwide: International survey," $B M J$, vol. 320, no. $7244,2000$.

[52] Ghana Statistical Service (GSS), 2010 Population \& Housing Census National Analytical Report, Ghana Statistical Service, Accra, Ghana, 2013.
[53] K. Victor Nyanteng and P. T. Peprah, "Lawford boateng acheamfuor ENOT. Report 2010 population and housing report," Regional Analytical Report, Ashanti Region, Kumasi, Ghana, 2013.

[54] K. A. Addo, R. J. Nicholls, S. N. A. Codjoe, and M. Abu, “A biophysical and socioeconomic review of the Volta delta, Ghana," Journal of Coastal Research, vol. 345, 2018.

[55] S. N. Cudjoe, T. Azure, C. Assem, and E. N. Nortey, Population and Housing Census Northern Regional Analytical Report, Ghana Statistical Service, Accra, Ghana, 2010.

[56] T. Adom, A. P. Kengne, A. De Villiers, and T. Puoane, "Prevalence of overweight and obesity among African primary school learners: a systematic review and meta-analysis," Obesity Science \& Practice, vol. 5, no. 5, 2019.

[57] R. Rosenheck, "Fast food consumption and increased caloric intake: a systematic review of a trajectory towards weight gain and obesity risk," Obesity Reviews, vol. 9, no. 6, 2008.

[58] R. W. Jeffery, J. Baxter, M. McGuire, and J. Linde, "Are fast food restaurants an environmental risk factor for obesity?" International Journal of Behavioral Nutrition and Physical Activity, vol. 3, no. 1, 2006.

[59] B. Davis and C. Carpenter, "Proximity of fast-food restaurants to schools and adolescent obesity," American Journal of Public Health, vol. 99, no. 3, 2009.

[60] J. Currie, S. D. Vigna, E. Moretti, and V. Pathania, "The effect of fast food restaurants on obesity and weight gain," American Economic Journal: Economic Policy, vol. 2, no. 3, 2010.

[61] A. Mohammadbeigi, A. Asgarian, E. Moshir et al., "Fast food consumption and overweight/obesity prevalence in students and its association with general and abdominal obesity," Journal of Preventive Medicine and Hygiene, vol. 59, no. 3, 2018.

[62] L. K. Fraser, G. P. Clarke, J. E. Cade, and K. L. Edwards, "Fast food and obesity: a spatial analysis in a large United Kingdom population of children aged 13-15," American Journal of Preventive Medicine, vol. 42, no. 5, 2012.

[63] C. A. Monteiro, W. L. Conde, B. Lu, and B. M. Popkin, "Obesity and inequities in health in the developing world," International Journal of Obesity, vol. 28, no. 9, 2004.

[64] C. L. Ogden, C. D. Fryar, C. M. Hales, M. D. Carroll, Y. Aoki, and D. S. Freedman, "Differences in obesity prevalence by demographics and urbanization in US Children and Adolescents, 2013-2016," JAMA, vol. 319, no. 23, 2018.

[65] A. Chirita-Emandi, C. G. Barbu, E. E. Cinteza et al., "Overweight and underweight prevalence trends in children from romania-pooled analysis of cross-sectional studies between 2006 and 2015," Obesity Facts, vol. 9, no. 3, 2016.

[66] S. Negash, C. Agyemang, T. E. Matsha, N. Peer, R. T. Erasmus, and A. P. Kengne, "Differential prevalence and associations of overweight and obesity by gender and population group among school learners in South Africa: a cross-sectional study," BMC Obesity, vol. 4, no. 1, 2017.

[67] J. A. O’Dea, "Gender, ethnicity, culture and social class influences on childhood obesity among Australian schoolchildren: implications for treatment, prevention and community education," Health \& Social Care in the Community, vol. 16, no. 3, 2008.

[68] A. Afshin, M. H. Forouzanfar, M. B. Reitsma et al., "Health effects of overweight and obesity in 195 countries over 25 years," New England Journal of Medicine, vol. 377, no. 1, 2017.

[69] A. R. Jones, M. J. Tovee, L. R. Cutler et al., "Health effects of overweight and obesity in 195 countries over 25 years," Yearbook of Paediatric Endocrinology, vol. 15, no. 2, 2018. 
[70] V. H. Wang, J. Min, H. Xue et al., "What factors may contribute to sex differences in childhood obesity prevalence in China?" Public Health Nutrition, vol. 21, no. 11, 2018.

[71] S. K. Muthuri, C. E. Francis, L. J. M. Wachira et al., "Evidence of an overweight/obesity transition among school-aged children and youth in Sub-Saharan Africa: a systematic review," PLoS One, vol. 9, no. 3, 2014.

[72] M. Carroll and N. Examination, Prevalence of Obesity Among Children and Adolescents: United States, Trends 1963-1965 through 2007-2008, CDC, Atlanta, GA, USA, 2010.

[73] H. Ranjani, T. S. Mehreen, R. Pradeepa et al., "Epidemiology of childhood overweight \& obesity in India: a systematic review," Indian Journal of Medical Research, vol. 143, no. 2, 2016. 